\title{
Imunidade passiva, morbidade neonatal e desempenho de cabritos em diferentes manejos de colostro ${ }^{1}$
}

INDEX TERMS: Immunity, immunoglobulins, colostrum, neonatal morbidity, performance, kids.

RESUMO.- Objetivando determinar o manejo de colostro que permitisse a melhor aquisição de imunidade passiva em cabritos e avaliar possíveis relações entre imunidade, morbidade e desempenho, amostras de sangue foram obtidas de 58 cabri-

\footnotetext{
${ }^{1}$ Recebido em 1 de abril de 2005.

Aceito para publicação em 6 de junho de 2005.

Parte da tese do primeiro autor no Programa de Doutorado Integrado em Zootecnia, Centro de Ciências Agrárias, Universidade Federal da Paraíba (UFPB).

${ }^{2}$ Doutoranda em Zootecnia, Centro de Ciências Agrárias, UFPB, Campus de Areia, 58397-000 Areia, PB. *Autor para correspondência. E-mail: saravilar@bol.com.br

${ }^{3}$ Centro de Formação de Tecnólogos, UFPB, Campus de Bananeiras, 58220-000 Bananeiras, PB.

${ }^{4}$ Centro de Ciências Biológicas da Saúde, Universidade Federal de Campina Grande (UFCG), Campina Grande, PB.

${ }^{5}$ Centro de Ciências Agrárias, UFPB.

${ }^{6}$ Aluna de Mestrado em Zootecnia, Centro de Ciências Agrárias, UFPB.
}

tos da raça Saanen antes e 30 horas após a primeira ingestão de colostro. Os cabritos foram distribuídos em cinco grupos experimentais. No Tratamento 1 (T1) o colostro foi ingerido ad libitum durante 24 horas. Nos demais tratamentos o colostro foi fornecido em mamadeira; os cabritos do T2 ingeriram $200 \mathrm{~mL}$ de colostro após o parto; do T3, ingeriram $400 \mathrm{~mL}$ de colostro sendo $200 \mathrm{~mL}$ após o parto e $200 \mathrm{~mL}$ após 8 horas; do T4, ingeriram também $400 \mathrm{~mL}$ de colostro, sendo $200 \mathrm{~mL}$ após o parto, $200 \mathrm{~mL}$ após 14 horas; e os do T5 ingeriram $600 \mathrm{~mL}$ de colostro, $200 \mathrm{~mL}$ após o parto, $200 \mathrm{~mL}$ as 12 e $200 \mathrm{~mL}$ as 24 horas. Os valores séricos de gamaglobulinas foram avaliados por eletroforese. $\mathrm{O}$ ganho de peso diário foi utilizado para avaliação do desempenho no período de aleitamento. A ocorrência de doenças foi registrada do nascimento até 28 dias. A menor concentração de gamaglobulinas foi encontrada nos animais do Grupo $2(1,65 \mathrm{~g} / \mathrm{dL})$ e a maior concentração foi observada no Grupo $3(2,60 \mathrm{~g} / \mathrm{dL})$. Foi observado no Grupo 3 mais animais com diarréia, porém não foram encontradas diferenças estatísticas significativas ao nível de 5\%. Os diferentes ma- 
nejos de colostro não estiveram associados com o desempenho dos cabritos até o final do período neonatal.

TERMOS DE INDEXAÇÃO: Imunidade, imunoglobulinas, colostro, morbidade neonatal, desempenho, cabritos.

\section{INTRODUÇÃO}

Em sistemas tradicionais de criação de caprinos ocorrem elevados índices de mortalidade das crias, registrando-se perdas significativas nos primeiros dias de vida, o que é muito prejudicial, já que se deseja obter o maior número possível de crias desmamadas/cabra/ano (Morand-Fehr 1987). Ao se tentar identificar a etiologia de uma doença os esforços iniciais estão, quase sempre, direcionados à identificação de um vírus, bactéria ou outro microrganismo específico. $\mathrm{O}$ isolamento e a identificação de agentes infecciosos são, freqüientemente, produtivos e necessários, mas, se não forem consideradas as interações manejo-doença, especialmente nas atividades intensivas, o controle do surto e a prevenção de surtos futuros podem ficar difíceis ou mesmo impossíveis (Aiello 2002). No manejo do período neonatal a ingestão do colostro representa uma das mais importantes recomendações dentro do conjunto de medidas sanitárias do rebanho.

Os neonatos ruminantes são expostos a um período de maior susceptibilidade à infecções que se estende desde o nascimento até apresentarem um sistema imunológico competente. A maior susceptibilidade dos ruminantes a infecções deve-se a placenta do tipo epitéliocorial, que leva ao bloqueio da passagem transplacentária de anticorpos. Quando um feto emerge do útero estéril para um ambiente onde é imediatamente exposto a microrganismos deve ser capaz de controlar uma invasão microbiana dentro de um período muito curto de tempo (Tizard 2002). Assim, é necessária a ingestão imediata do colostro de forma que adquira anticorpos de forma passiva. Trabalhos de O'Brien \& Sherman (1993) e Constant et al. (1994) tratam das relações entre baixas concentrações de imunoglobulinas séricas e perdas de cabritos por causas infecciosas. Quando os neonatos não conseguem absorver quantidades suficientes de anticorpos colostrais chegam a uma condição que recebe a denominação de falha na transferência passiva de imunidade (FTP). Atraso na ingestão de colostro, ingestão de pequenas quantidades, ou ambos os fatores, freqüientemente resultam em falhas de transferência passiva de imunidade (Brignole \& Stott 1980, Besser et al. 1991).

Além de sua função na imunidade neonatal o colostro é uma importante fonte de proteínas, carboidratos, lipídeos, vitaminas e sais minerais; elementos que participam da nutrição e regulação térmica do recém-nascido (Machado Neto 2001). O colostro também contém hormônios, fatores de crescimento e enzimas, que possuem atividades associadas à maturação do trato digestivo e outros sistemas, desempenhando importante papel no crescimento e desenvolvimento do recém-nascido (Odle et al. 1996). Desta forma, é preciso estudar também a importância da ingestão do colostro no desempenho dos cabritos, o que é extremamente importante, pois o ganho de peso durante os primeiros meses de vida é crítico para o subseqüiente desenvolvimento e influencia diretamente na idade a primeira parição e outros aspectos produtivos.

A avaliação da aquisição de imunidade passiva pode ser feita através da dosagem da proteína sérica total e de suas frações antes e após a ingestão de colostro; este procedimento permite quantificar a fração gama das globulinas absorvida, que incluem as imunoglobulinas ou anticorpos. A quantidade de gamaglobulinas capaz de assegurar a sobrevivência dos bezerros já foi bem estudada e estabelecida. Porém, a adequada concentração inicial de gamaglobulinas no soro de cabritos não tem sido suficientemente estudada, especialmente em cabritos submetidos a diferentes manejos na fase de colostro. Este trabalho teve como objetivo identificar o manejo de colostro capaz de assegurar a maior aquisição de gamaglobulinas, verificar a influência deste manejo na morbidade e mortalidade de cabritos e avaliar o efeito dos diferentes manejos no desempenho de cabritos durante o período neonatal.

\section{MATERIAL E MÉTODOS}

Quarenta e duas fêmeas caprinas da raça Saanen foram mantidas em regime de semiconfinamento até o final do último mês de gestação. À medida que as parições ocorreram, as crias foram pesadas e tiveram uma amostra de sangue retirada antes da ingestão de colostro. A seguir, utilizando um delineamento inteiramente casualizado, foram distribuídas em cinco grupos experimentais e submetidas a cinco manejos de colostro (tratamentos). O Grupo 1 foi formado por 10 cabritos que permaneceram com a mãe 24 horas e ingeriram colostro ad libitum (Tratamento 1). Os demais grupos foram formados por 12 cabritos cada. $\mathrm{O}$ Grupo 2 recebeu um único fornecimento de $200 \mathrm{~mL}$ de colostro na primeira hora após o parto (Tratamento 2). 0 Grupo 3 recebeu $200 \mathrm{~mL}$ de colostro na primeira hora após o parto e oito horas após a primeira ingestão tiveram acesso novamente a $200 \mathrm{~mL}$ (Tratamento 3). O Grupo 4 recebeu $200 \mathrm{~mL}$ de colostro na primeira hora após o parto e 14 horas após a primeira ingestão tiveram acesso novamente a $200 \mathrm{~mL}$ (Tratamento 4). O Grupo 5 foi formado por cabritos que receberam $200 \mathrm{~mL}$ de colostro na primeira hora após o parto e às 12 e 24 horas após a primeira ingestão tiveram acesso a novo fornecimento de $200 \mathrm{~mL}$ de colostro (Tratamento 5). Os animais dos Grupos 2, 3 4, e 5, que receberam colostro em mamadeiras tiveram o colostro retirado da mãe no momento da ingestão. Durante o período neonatal, que durou 28 dias, os animais foram mantidos em cabriteiro coletivo e aleitados artificialmente duas vezes ao dia com $400 \mathrm{~mL}$ de leite de vaca, perfazendo um total de $800 \mathrm{~mL} /$ dia. A partir da primeira semana de vida foi permitido acesso à ração completa composta de $80 \%$ de concentrado e $20 \%$ de volumoso para todos os grupos.

As colheitas de sangue para a obtenção de soro, realizadas ao nascimento e 30 horas após, foram efetuadas através de punção na veia jugular utilizando-se agulhas $25 \times 8 \mathrm{~mm}$ acopladas a tubos vacutainer siliconizados com $4 \mathrm{~mL}$ de capacidade. $O$ sangue foi mantido à temperatura ambiente até coagulação e retração do coágulo. As amostras foram então centrifugadas a 3.000 rpm durante 10 minutos e o soro obtido foi armazenado a $-20^{\circ} \mathrm{C}$. Para a realização das avaliações laboratoriais o descongelamento das amostras foi feito deixando-as a temperatura ambiente.

A proteína total foi determinada pelo método do Biureto, segundo Gornal et al. (1949) modificado por Strufaldi (1987), utilizando-se kit apropriado $^{7}$ e foi mensurada utilizando-se analisador bioquímico semiautomático $^{8}$. A migração eletroforética, para separação das frações protéicas do soro, foi efetuada em placa de gel de agarose segundo as técnicas citadas por Strufaldi (1987). O percentual de cada fração protéica foi medido por leitura em densitômetro digital de varredura ${ }^{9}$.

\footnotetext{
${ }^{7}$ Labtest.

${ }^{8}$ Bioplus 2000.

${ }^{9}$ DS 35 - CELM.
} 
Os cabritos foram submetidos a avaliações clínicas periódicas até o final do período neonatal. A incidência de doenças foi definida como qualquer condição requerendo pelo menos uma intervenção medicamentosa. Os animais que adoeceram durante o período experimental foram medicados de acordo com o diagnóstico nosológico realizado.

Os 58 cabritos que formaram os cinco grupos experimentais foram identificados e pesados antes da primeira ingestão de colostro. $\mathrm{O}$ ganho de peso diário foi utilizado para determinar o desempenho, sendo feita a pesagem um dia por semana antes do primeiro fornecimento de leite.

Para a obtenção dos valores de referência dos constituintes do soro sangüíneo dos cabritos com 0 h e 30 h de vida foi realizada a estatística descritiva para determinação dos valores de tendência central e dos valores de dispersão para cada variável estudada. Os animais foram considerados com falha de transferência de imunidade passiva (FTP) quando apresentaram níveis séricos de proteína total e gamaglobulinas inferiores a um desvio padrão abaixo da média mensurada às 30 horas de vida. A opção por esse parâmetro segue os critérios adotados por McGuire et al. (1976) e Moraes et al. (1997) em bovinos.

As possíveis influências dos tratamentos sobre as variáveis estudadas foram determinadas através de análise de variância. A comparação de médias foi feita através do teste Tukey, assumindo 5\% de probabilidade. Análises de correlação foram efetuadas para verificar associações entre as variáveis que fossem consideradas de interesse para o estudo.

\section{RESULTADOS}

Os valores da proteína total e suas frações, antes da ingestão de colostro, estão demonstrados no Quadro 1 . O valor médio da proteína total foi de $3,86 \pm 0,4 \mathrm{~g} / \mathrm{dL}$ e não foram encontradas diferenças estatísticas significativas entre os grupos. 0 fracionamento da proteína total demonstrou em todos os grupos o predomínio da fração albumina sobre a fração globulina. Dentre a fração globulina o valor de alfa-globulina do Grupo 3 foi menor que o obtido nos demais grupos, com diferenças estatísticas significativas dos valores obtidos nos Grupos 1 e 2. Todos os grupos experimentais apresentaram sempre níveis mais elevados da fração beta em relação à fração alfa. Não foi identificada a presença de gamaglobulina em nenhum grupo experimental.

Os valores da proteína sérica total e seu fracionamento após ingestão do colostro estão registrados no Quadro 2. Observouse elevação nos níveis de proteína total em todos os grupos

Quadro 1. Valores médios de proteína total, albumina, alfa, beta e gama globulina no soro de cabritos da raça Saanen antes da ingestão de colostro

\begin{tabular}{cccccc}
\hline Grupos & $\begin{array}{c}\text { Proteína } \\
\text { total* }\end{array}$ & Albumina & $\begin{array}{c}\text { Alfa-glo- } \\
\text { bulina }\end{array}$ & $\begin{array}{c}\text { Beta-glo- } \\
\text { bulina }\end{array}$ & $\begin{array}{c}\text { Gama-glo- } \\
\text { bulina }\end{array}$ \\
\hline 1 & $3,99^{\mathrm{a}}$ & $2,54^{\mathrm{a}}$ & $0,64^{\mathrm{a}}$ & $0,81^{\mathrm{a}}$ & $\mathrm{Nd}^{\text {*** }}$ \\
2 & $4,00^{\mathrm{a}}$ & $2,57^{\mathrm{a}}$ & $0,65^{\mathrm{a}}$ & $0,78^{\mathrm{a}}$ & $\mathrm{Nd}$ \\
3 & $3,78^{\mathrm{a}}$ & $2,60^{\mathrm{a}}$ & $0,47^{\mathrm{b}}$ & $0,71^{\mathrm{a}}$ & $\mathrm{Nd}$ \\
4 & $3,75^{\mathrm{a}}$ & $2,46^{\mathrm{a}}$ & $0,57^{\mathrm{ab}}$ & $0,72^{\mathrm{a}}$ & $\mathrm{Nd}$ \\
5 & $3,78^{\mathrm{a}}$ & $2,59^{\mathrm{a}}$ & $0,56^{\mathrm{ab}}$ & $0,63^{\mathrm{a}}$ & $\mathrm{Nd}$ \\
\hline
\end{tabular}

* Médias seguidas de letras diferentes na mesma coluna diferem estatisticamente $(\mathrm{P}<0,05)$ pelo teste de Tukey.

*** Nd = Não detectada.
Quadro 2. Valores médios de proteína total, alfa, beta e gamaglobulina no soro de cabritos da raça Saanen $\mathbf{3 0}$ horas após ingestão de colostro em diferentes manejos

\begin{tabular}{lccccc}
\hline $\begin{array}{c}\text { Fornecimento } \\
\text { de colostro }\end{array}$ & $\begin{array}{c}\text { Proteína } \\
\text { total* }\end{array}$ & Albumina & $\begin{array}{c}\text { Alfa-glo- } \\
\text { bulina }\end{array}$ & $\begin{array}{c}\text { Beta-glo- } \\
\text { bulina }\end{array}$ & $\begin{array}{c}\text { Gama-glo- } \\
\text { bulina }\end{array}$ \\
\hline T1-a vontade & $6,63^{\mathrm{ab}}$ & $2,64^{\mathrm{a}}$ & $0,74^{\mathrm{a}}$ & $0,78^{\mathrm{a}}$ & $2,47^{\mathrm{ab}}$ \\
T2-2 h & $5,77^{\mathrm{b}}$ & $2,62^{\mathrm{a}}$ & $0,65^{\mathrm{ab}}$ & $0,85^{\mathrm{a}}$ & $1,65^{\mathrm{b}}$ \\
T3-2 e $8 \mathrm{~h}$ & $7,00^{\mathrm{a}}$ & $2,74^{\mathrm{a}}$ & $0,74^{\mathrm{b}}$ & $0,87^{\mathrm{a}}$ & $2,60^{\mathrm{a}}$ \\
T4-2 e 14h & $6,00^{\mathrm{ab}}$ & $2,68^{\mathrm{a}}$ & $0,64^{\mathrm{ab}}$ & $0,82^{\mathrm{a}}$ & $1,86^{\mathrm{b}}$ \\
T5-2, 12 e 24h & $6,30^{\mathrm{ab}}$ & $2,63^{\mathrm{a}}$ & $0,57^{\mathrm{b}}$ & $0,78^{\mathrm{a}}$ & $2,30^{\mathrm{ab}}$
\end{tabular}

* Médias seguidas de letras diferentes na mesma coluna diferem estatisticamente $(\mathrm{p}<0,05)$ pelo teste de Tukey.

experimentais, que obtiveram uma média de $6,4 \pm 1,3 \mathrm{~g} / \mathrm{dL}$. Registrou-se diferença significativa entre os animais do Grupo 2 $(5,77 \mathrm{~g} / \mathrm{dL})$ e $3(7,0 \mathrm{~g} / \mathrm{dL})$, que foram submetidos, respectivamente, ao Tratamento 2 (apenas uma ingestão de colostro após o parto) e Tratamento $3(200 \mathrm{~mL}$ de colostro na primeira hora e nova ingestão oito horas após o parto).

$O$ valor médio de albumina após ingestão de colostro foi $2,66 \pm 0,36 \mathrm{~g} / \mathrm{dL}$. Registrou-se elevação nas frações protéicas alfa e beta-globulina que passaram a valores médios de $0,67 \pm 0,14 \mathrm{~g}$ / dL e $0,82 \pm 0,16 \mathrm{~g} / \mathrm{dL}$. Não foram observadas diferenças estatísticas entre os grupos ao se analisar os valores médios de albumina. A fração alfa-globulina apresentou diferenças significativas entre os Grupos 1 e 5 e estes não diferiram dos demais. A fração beta-globulina não apresentou diferenças significativas entre os grupos e o nível de gamaglobulinas passou de valores não mensuráveis para $2,18 \pm 0,97 \mathrm{~g} / \mathrm{dL}$. Na análise estatística dos dados foi identificada diferença significativa na fração gamaglobulina entre os animais dos Grupos 2 e 3 . A menor média foi obtida pelo Grupo $2(1,65 \mathrm{~g} / \mathrm{dL})$ e a maior média foi obtida pelos Grupo $3(2,60 \mathrm{~g} / \mathrm{dL})$. Análises individuais dos níveis séricos de gamaglobulina mostraram variações de 0,2 a $4,9 \mathrm{~g} / \mathrm{dL}$ o que levou à condição de FTP em 7 (12,06\%) dos 58 cabritos. Nas análises de correlação foi detectada alta correlação positiva entre os valores de proteína total e gamaglobulinas $(\mathrm{r}=0,83 ; \mathrm{P}<$ 0,001).

As doenças observadas durante o período neonatal estão descritas no Quadro 3. Estão registrados os casos de diarréia e conjuntivite. Nenhuma outra enfermidade foi observada. A taxa de morbidade registrada foi de $32,75 \%$ sendo identificados cinco casos de conjuntivite $(8,86 \%)$ e 14 casos de diarréia $(24,13 \%)$.

As diferentes ofertas de colostro e as médias de peso ao

\section{Quadro 3. Morbidade neonatal de cabritos da raça Saanen} submetidos a diferentes ofertas de colostro

\begin{tabular}{cccccc}
\hline $\begin{array}{c}\text { Fornecimento de colostro Número de } \\
\text { (horas após o parto) }\end{array}$ & $\begin{array}{c}\text { Casos de } \\
\text { animais }\end{array}$ & $\begin{array}{c}\text { Casos de } \\
\text { diarréia }\end{array}$ & $\begin{array}{c}\text { Morbidade* } \\
\text { conjuntivite }\end{array}$ & $\begin{array}{c}\text { n } \\
\%\end{array}$ \\
\hline T1 - a vontade & 10 & 2 & 2 & 4 & $40,0 \%$ \\
T2 - 2 h & 12 & 1 & - & 1 & $8,33 \%$ \\
T3 - 2 e 8h & 12 & 5 & 1 & 6 & $50,0 \%$ \\
T4 - 2 e 14 & 12 & 3 & 1 & 4 & $33,3 \%$ \\
T5 - 2, 12 e 24h & 12 & 3 & 1 & 4 & $33,3 \%$ \\
Total 58 & 14 & 5 & 19 & $32,7 \%$
\end{tabular}

* Diferenças não significativas ao nível de 5\% pelo teste do qui-quadrado. 
Quadro 4. Médias do peso ao nascer, peso aos 28 dias (final do período neonatal) e ganho diário de peso de cabritos da raça Saanen submetidos a diferentes ofertas de colostro

\begin{tabular}{cccc}
\hline $\begin{array}{c}\text { Fornecimento de colostro } \\
\text { (horas após o parto) } \\
\text { (g/dia) }\end{array}$ & $\begin{array}{c}\text { Peso ao nascer } \\
(\mathrm{kg})^{*}\end{array}$ & $\begin{array}{c}\text { Peso aos } 28 \\
\text { dias }(\mathrm{kg})\end{array}$ & $\begin{array}{c}\text { Ganho de peso } \\
\text { durante período } \\
\text { neonatal }\end{array}$ \\
\hline T1 - a vontade & $2,98^{\mathrm{a}}$ & $5,11^{\mathrm{a}}$ & $76,1^{\mathrm{a}}$ \\
T2 - 2 h & $2,83^{\mathrm{a}}$ & $5,20^{\mathrm{a}}$ & $80,0^{\mathrm{a}}$ \\
T3 - 2 e $8 \mathrm{~h}$ & $2,98^{\mathrm{a}}$ & $5,37^{\mathrm{a}}$ & $85,3^{\mathrm{a}}$ \\
T4 - 2 e 14 & $2,90^{\mathrm{a}}$ & $5,19^{\mathrm{a}}$ & $81,8^{\mathrm{a}}$ \\
T5 - 2, 12 e 24h & $2,69^{\mathrm{a}}$ & $5,16^{\mathrm{a}}$ & $88,2^{\mathrm{a}}$ \\
\hline
\end{tabular}

${ }^{*}$ Médias seguidas de letras diferentes na mesma coluna diferem estatisticamente $(\mathrm{P}<0,05)$ pelo teste de Tukey.

nascer e ao final do período neonatal estão especificadas no Quadro 4. No aspecto do desempenho não foram registradas diferenças significativas entre os grupos nas médias de peso ao final do período neonatal

\section{DISCUSSÃO E CONCLUSÕES}

Os baixos níveis de proteína total antes da ingestão do colostro são justificados pela ausência da fração gamaglobulina do soro dos neonatos. A agamaglobulinemia, antes da ingestão do colostro; também foi observada em cabritos (Constant et al. 1994) e bezerros (Feitosa 1998) que ressaltaram que, na maioria dos animais recém-nascidos, o plasma sangüíneo apresenta pequena concentração desta fração, chegando em alguns animais a estar ausente no sangue, em consequiência da placenta não ser permeável às moléculas de gamaglobulinas. As variações observadas na fração alfa das globulinas, antes e após a ingestão de colostro são de difícil interpretação pois, segundo Schalm et al. (1975) nesta fração encontram-se várias frações protéicas como alfa-1-lipoproteínas, alfa-1-glicoproteínas, transcortina, tiroxinaligada-globulina, haptoglobulina, ceruloplasmina e colinesterase, e este grupo de substâncias pode apresentar variações em estados fisiológicos e patológicos.

A elevação da proteína sérica total após ingestão de colostro foi decorrente da absorção de gamaglobulinas que estão presentes em grandes quantidades no colostro. Para a zona gama das globulinas migram todas as globulinas que têm função de anticorpo. $\mathrm{O}$ nível de gamaglobulinas passou de valores não mensuráveis para $2,18 \pm 0,97 \mathrm{~g} / \mathrm{dL}$. A correlação positiva e altamente significativa entre os valores de proteína total e gamaglobulinas demonstra que a determinação da proteína sérica total é um método eficaz de avaliação da aquisição de imunidade passiva. Lopez et al. (1988) também verificaram correlação significativa entre a proteína sérica total e a concentração de gamaglobulina após ingestão de colostro $(\mathrm{r}=0,70 ; \mathrm{P}<$ 0,01 ) em bezerros. A aquisição de gamaglobulinas justifica também o predomínio da fração globulina sobre a fração albumina após ingestão do colostro.

Selin et al. (1995) consideraram o nível de $1,5 \mathrm{~g} / \mathrm{dL}$ de gamaglobulinas como sendo satisfatório para fornecer boa imunidade a bezerros. Desta forma, apesar de serem espécies diferentes, pode-se considerar que o fornecimento de colostro em todos os grupos experimentais assegurou aquisição de uma boa imunidade passiva aos cabritos. Esta última afirmação pode ser respaldada pelo fato de, aparentemente, os níveis de imunoglobulinas necessários aos cabritos serem menores do que os exigidos para bezerros, pois Nandakumar \& Rajagopalaraja (1983) relataram que cabritos com concentração de imunoglobulina sérica a partir de $0,8 \mathrm{~g} / \mathrm{dL}$ tiveram taxas de morbidade e mortalidade menores que o grupo de cabritos com concentrações menores que $0,4 \mathrm{~g} / \mathrm{dL}$. A necessidade de menores taxas de gamaglobulinas fica também evidente na pesquisa conduzida por Constant et al. (1994) na qual cabritos com menos que $0,4 \mathrm{~g} / \mathrm{dL}$ de gamaglobulinas não adoeceram. No entanto, as condições higiênico-sanitárias foram consideradas satisfatórias e os autores sugeriram que os bons resultados obtidos estavam associados, possivelmente, ao bom manejo da fazenda.

O fato dos Grupos 1, 2, 4 e 5, que tiveram manejos de colostro bem diferenciados, não terem diferido estatisticamente na concentração de proteína total e gamaglobulinas é um aspecto que chama atenção. A ausência de diferenças significativas entre estes grupos, especialmente o Grupo 2, que teve acesso a apenas uma parcela de $200 \mathrm{~mL}$ de colostro, demonstra a importância de se fornecer precocemente a parcela inicial de colostro, realizada em todos os grupos na primeira hora após o parto. Além da precocidade da ingestão de colostro a aquisição de bons níveis de gamaglobulinas pelo Grupo 2 justifica-se pelo fato de ter sido garantida a ingestão de um volume inicial satisfatório. Considerando o peso médio ao nascimento do grupo $(2,8 \mathrm{~kg})$ a ingestão de $200 \mathrm{~mL}$ de colostro equivale a $7 \%$ do seu peso, valor bem próximo ao preconizado como satisfatório, que varia de 8 a $10 \%$ do peso nas primeiras 12 horas de vida. Os resultados obtidos estão de acordo com a opinião de Mensik et al. (1977) que consideraram 1 que a concentração de imunoglobulinas no soro de bezerros depende da quantidade da primeira ingestão e não foi influenciada pela quantidade de colostro dada aos bezerros nas demais doses.

Apesar da importância da ingestão inicial ser feita o mais precocemente possível, deve-se atentar para o fato que este procedimento também acelera o "fechamento" do intestino (Stott et al. 1979), o que chega a ser um ponto positivo, pois agentes patogênicos também se incluem entre as macromoléculas podendo ser absorvidos e gerar infecções. Desta forma é preciso assegurar ingestões precoces, porém em volumes adequados.

Ao se analisar, separadamente dos demais grupos, os animais dos Grupos 3 e 4 observa-se que ambos ingeriram $400 \mathrm{~mL}$ de colostro, sendo as outras ingestões de $200 \mathrm{~mL}$ de colostro realizadas, respectivamente, às 8 e 14h após o parto e a média da fração gamaglobulina do Grupo $4(1,86 \mathrm{~g} / \mathrm{dL})$ foi a segunda menor obtida. Os resultados demonstram que a eficiência de absorção da segunda ingestão é prejudicada caso seja ultrapassado o limite das 8 horas após o parto. Tood \& Whyte (1995), estudando o tempo de fornecimento do colostro após o nascimento, demonstraram que grupos de bezerros que receberam colostro uma só vez em períodos que variaram de 2 a 8 h após o nascimento não possuíam diferenças nas concentrações médias de gamaglobulinas. Os resultados obtidos pelos pesquisadores e a interpretação dos resultados obtidos nesta pesquisa com cabritos sugerem que a realização da segunda ingestão de 
colostro até as 8 horas após o nascimento é também importante na elevação dos valores de gamaglobulinas.

Apesar dos bons resultados, quando se considera a média de gamaglobulinas de todos os grupos, ao se examinar os valores individuais dos 58 cabritos observou-se que foram registradas variações de 0,2 até $4,9 \mathrm{~g} / \mathrm{dL}$, o que demonstra que houve falha de transferência de imunidade em alguns animais. Na literatura também foi encontrada grande variação nos valores obtidos em bezerros nas primeiras 48 horas de vida. Brignole \& Stott (1980) encontraram concentrações médias de $1,13 \mathrm{~g} / \mathrm{dL}$ e variações de 0 a $6,3 \mathrm{~g} / \mathrm{dl}$. A falha de transferência passiva, mesmo sob ingestão controlada de colostro, pode ser decorrente de fatores individuais como acidose respiratória pós-natal ou prematuridade do feto (Johnston \& Stewart 1986, Besser et al. 1990). Em alguns animais ocorre ainda a perda precoce da capacidade de absorção intestinal do colostro (Stott et al.1979).

Foram identificados 7 cabritos $(12,06 \%)$ com FTP nos grupos quando se considerou os critérios propostos neste experimento; ou seja, animais portadores de falha de transferência passiva de imunidade seriam aqueles que apresentassem níveis de gamaglobulinas inferiores a um desvio padrão abaixo da média da população estudada. No grupo que ingeriu colostro ad libitum na mãe registrou-se falha individual de transferência de imunidade em um cabrito, que corresponde a um percentual de $10 \%$. A condição de FTP de imunidade parece ser menos freqüente em cabritos do que em bezerros, talvez devido ao comportamento mais ativo dos caprinos após o nascimento. Brignole \& Stott (1980) e Besser et al. (1991) relataram, respectivamente, que $40 \%$ e $61 \%$ dos bezerros falharam em obter suficiente imunidade passiva quando deixados com a mãe por um dia. Os Grupos 2, 4 e 5 tiveram, cada um, dois cabritos com valores abaixo de $1,21 \mathrm{~g} / \mathrm{dL}$ de gamaglobulinas, o que nos mostra um percentual de $16,6 \%$ de animais com FTP, resultado um pouco maior que o obtido nos animais que mamaram livremente nas mães. Este resultado é inverso ao descrito em bezerros. Segundo Rajala \& Castren (1995) 33\%, dos animais que mamaram nas próprias mães ficaram com falhas parciais de transferência de imunidade $(0,8-1,6 \mathrm{~g} / \mathrm{dL}$ de imunoglobulinas) e apenas $7 \%$ dos animais que tiveram fornecimento de colostro em mamadeira tiveram falhas parciais. Não foram identificadas FTP individuais nos animais do Grupo 3.

Dentre os animais que foram acometidos de diarréia observa-se que 5 pertenciam ao Grupo 3, animais que vinham apresentando os melhores indicadores de aquisição de imunidade. Nos animais do Grupo 2, que receberam apenas uma ingestão de colostro, registro-se apenas um animal com diarréia. Porém, na análise estatística através do teste de qui-quadrado não foi observada diferença significativa na morbidade entre os grupos ao nível de significância de 5\%. Apesar da não significância estatística não devemos desconsiderar os resultados; a menor concentração de gamaglobulinas nos animais do Grupo 2 pode ter estimulado o início da capacitação imunológica e determinado a produção precoce de imunoglobulina endógena, que caracteriza a formação de imunidade ativa. Dentre os animais com conjuntivite e diarréia não ocorreu nenhum óbito durante o período neonatal, no entanto, deve-se ressaltar que os animais foram medicados de acordo com o diagnóstico nosológico rea- lizado, podendo ter ocorrido mortalidade em condições em que não estivesse ocorrendo o acompanhamento clínico.

Apesar de obter melhor aquisição de imunidade, considerando os valores de proteína total e gamaglobulinas, o Grupo 3 não se diferenciou dos demais grupos no ganho diário de peso. Na literatura são também encontrados relatos que não associam ganho de peso e imunidade. Edwards et al. (1982), Shell et al. (1995) e Machado Neto et al. (1997) não encontraram correlação entre os níveis séricos de anticorpos nas primeiras 48 horas de vida e o ganho de peso diário até a desmama.

Em pesquisa realizada por Moraes et al. (2000) não foram registradas diferenças na média diária de ganho de peso entre os animais com falha de transferência passiva de imunidade (FTP) e aqueles com adequada imunidade passiva no período do nascimento ao desmame. No entanto, ao redor de 13 a 16 meses de idade o grupo com FTP ganhou menos peso do que aqueles com boa aquisição de imunidade passiva. Para que se pudesse avaliar, com maior segurança, prováveis influências da aquisição de imunidade passiva no desempenho seria necessário estender o período de avaliação por um período mais prolongado de tempo.

Wittum \& Perino (1995) observaram que animais com falha de transferência passiva ganharam menos peso do que animais com adequada transferência passiva de imunidade, mas consideraram isto como sendo um efeito indireto da morbidade aumentada nos animais com falha de transferência passiva de imunidade. Concentrações insuficientes de imunoglobulinas às $24 \mathrm{e}$ $48 \mathrm{~h}$ podem levar o neonato a uma invasão de organismos patogênicos. As doenças associadas com estas invasões prejudicam o normal desenvolvimento da cria. Essas informações são confirmadas pelo trabalho de Crawford et al. (1995), que em estudo experimental onde mantiveram bezerros sob rigorosas práticas de higiene, observaram que a ingestão de alimentos e o ganho de peso foram similares entre os bezerros alimentados com colostro e entre aqueles que permaneceram hipogamaglobulinêmicos.

Em relação ao manejo de colostro concluímos que o fornecimento de duas parcelas de $200 \mathrm{~mL}$, sendo a primeira efetivada logo após o nascimento, e a segunda até 8 horas após o parto, assegurou a aquisição de bons níveis de imunidade passiva. Esse tipo de informação é similar à fornecida para bezerros e o manejo ideal para bezerros já foi proposto por diversos pesquisadores, no entanto, a falha na transferência passiva de imunidade é ainda um problema que ocasiona graves prejuízos na bovinocultura. Tal situação nos leva a pensar que, repetir os estudos, comumente feitos em bezerros, nos cabritos e cordeiros, pode nos remeter a situações semelhantes. Desta forma, devemos ter consciência que identificar manejos de colostro que assegurem boa aquisição de imunidade é apenas um aspecto na sanidade dos caprinos jovens e que esta deve ser avaliada de forma ampla para que realmente possa ser minimizada. É necessário, mediante pesquisas, obter dados sob o estado imunológico e observar um maior número de animais para que se possa fazer, em cabritos, associações entre morbidade/ mortalidade e imunidade passiva nas condições de nossa região. As condições higiênico-sanitárias dos rebanhos precisam também ser consideradas e são necessárias avaliações do impacto deste aspecto na morbidade e mortalidade neonatal, pois, mesmo com 
a aquisição de bons níveis de anticorpos, se a pressão de infecção no ambiente é muito alta, podem ocorrer altas taxas de morbidade e mortalidade.

\section{REFERÊNCIAS}

Aiello S.E. 2002. Manual Merck de Veterinária. $8^{\underline{a}}$ ed. Roca, São Paulo. $1861 \mathrm{p}$.

Besser T.E., Gay C.C. \& Pritchett L. 1991. Comparison of three methods of feeding colostrums to dairy calves. J. Am. Vet. Med. Assoc. 198:419-422.

Besser T.E., Szenci O. \& Gay C.C. 1990. Decreased colostral immunoglobulins absorption in calves with postnatal respiratory acidosis. J. Am. Vet. Med. Assoc. 196:1239-1243.

Brignole T.J. \& Stott G.H. 1980. Effect of suckling followed by bottle feeding colostrum on immunoglobulin absorption and calf survival. J. Dairy Sci. 63:451-456.

Constant S.B., Leblanc M.M., Klapstein E.F., Beebe D.E., Leneau H. M. \& Nunier C.J. 1994. Serum immunoglobulin G concentration in goat kids fed colostrum or a colostrums substitute. J. Am. Vet. Med. Assoc. 205:1759-1762.

Crawford M.L., Quigley J.D. \& Martin K.R. 1995. Immunoglobulin concentrations in serum in response to injectable immunoglobulin in neonatal dairy calves. J. Dairy Sci. 78:1567-1572.

Edwards S.A., Broom D.M. \& Collis S. 1982. Factors affecting levels of passive immunity in dairy calves. Brit. Vet. J. 138:233-240.

Feitosa, F.L.F. 1998. Dinâmica do proteinograma e da atividade da gamaglutamiltransferase no soro sangüíneo de bezerros desde o nascimento até os 365 dias de idade e de vacas, antes e após o parto, da raça holandesa. Tese de Doutorado em Clinica Médica, Faculdade de Medicina Veterinária e Zootecnia, USP, São Paulo. 219p.

Gornall A.G., Bardawill C.J. \& David M.M. 1949. Determination of serum protein by means of biuret reaction. J. Biol. Chem. 177:751-766.

Johnston N.E. \& Stewart J.A. 1986. The effect of glucocorticoids and prematurity on absorption of colostral immunoglobulins in the calf. Aust. Vet. J. 63:191-192.

Lopez J. W., Allen S. D., Mitchell J \& Quinn M. 1988. Rotavirus and Cryptosporidium shedding in dairy calf feces and its relationship to colostrums immune transfer. J. Dairy Sci. 71:1288-1294.

Machado Neto R., Packer I.V., Bonilha L.M., Figueredo L.A ., Razzok A.G. \& Candido J.G. 1997. Concentração de IgG sérica em bezerros das raças nelores, guzerá, gir, caracu. 2. Efeitos sobre o crescimento e mortalidade até a desmama. Revta Bras. Zootec. 26:920-923.

Machado Neto R. 2001. Formação e transferência da imunidade passiva. Anais 38 ${ }^{\mathrm{a}}$ Reun. Soc. Bras. Zootec., FEALQ, Piracicaba, p.644-657.

McGuire T.C., Pfeiffer N.E., Weikel J.M. \& Bartsch R.C. 1976. Failure of colostral immunoglobulin transfer in calves dying by infectious diseases. J. Am. Vet. Med. Assoc. 169:713-718.
Mensik J., Dressler J., Franz J. \& Pokorny J. 1977. Effect of different systems of colostral nutrition on the level of immunoglobulins in the blood of calves Vet. Med. 22:449-461.

Moraes M.P., Weiblen R., Silva A.M. \& Tobias F.L. 1997. Evolução da imunidade passiva em fêmeas bovinas da raça holandesa. Ciência Rural, Santa Maria, 27:435-440.

Moraes M.P., Weiblen R., Rebelatto M.C. \& Silva A.M. 2000. Relação entre imunidade passiva e morbidade e ganho de peso em bovinos leiteiros. Ciência Rural, Santa Maria, 30:299-304.

Morand-Fehr P. 1987. Management programs for the prevention of kids losses. Proc. 4th Int. Conference on Goats, Brasília, p.405-423.

Nandakumar P., \& Rajagopalaraja C.A .1983. Effect of genetic group, birth weight and type of birth on the post colostral peak of serum immunoglobulin level in kids. Kerala J. Vet. Sci. 14:53-56.

O'Brien J.P.\& Sherman D.M. 1993. Serum immunoglobulin concentrations of newborn goat kids and subsequent kid survival through weaning. Small Rumin. Res. 11:71-77.

Odle J., Zijlstra R. T. \& Donovan S. M. 1996. Intestinal effects of milkborne growth factors in neonates of agricultural importance. J. Anim. Sci. 74:2509-2522.

Rajala P. \& Castrén H. 1995. Serum immunoglobulin concentrations and health of dairy calves in two management systems from birth to 12 weeks of age. J. Dairy Sci. 78:2737-2774.

Schalm O.W., Jain N.C. \& Carrol E.J. 1975. Veterinary Hematology. 3rd ed. Lea \& Febiger, Philadelphia . 807p.

Selin S.A ., Smith B.P., Cullor J.S. \& Blanchard P. 1995. Serum immunoglobulins in calves. Their effects and two easy reliable means of measurement. Vet. Med. 90:387-404.

Shell T.M., Early R. J., Carpenter J.R. \& Buckley B.A. 1995. Prepartum nutrition and solar radiation in beef cattle. II. Residual effects on postpartum milk yield, immunoglobulin and calf growth. J. Anim. Sci. 73:1303-1309.

Stott G.H, Marx D.B., Menefee B.E., Nightengale G.T. 1979. Colostral immunoglobulin transfer in calves. I. Period of absorption. J. Dairy Sci. 62:1632-1638.

Strufaldi B. 1987. Prática de bioquímica clínica. Faculdade de Ciências Farmacêuticas, USP, São Paulo. 339p.

Tizard I.R. 2002. Imunologia Veterinária - uma introdução. 6 6 ed. Roca, São Paulo. 532p.

Tood A.G. \& Whyte P.B.D. 1995. The effect of delays on feeding colostrums and the relationship between immunoglobulin concentration in the serum of neonatal calves and their rates of growth. Aust. Vet. J. 72:415417.

Wittum T.E. \& Perino L.J. 1995. Passive immune status at postpartum hour 24 and long-term health and performance of calves. Am. J. Vet. Res. 56:1149-1154. 